\title{
Effect of Deep Cryogenic Heat Treatment on the Wear Behavior of Carburized DIN 1.7131 Grade Steel
}

\author{
Kamran Amini · AliReza Araghi · Amin Akhbarizadeh
}

Received: 11 May 2014/Revised: 22 July 2014/Published online: 14 January 2015

(C) The Chinese Society for Metals and Springer-Verlag Berlin Heidelberg 2015

\begin{abstract}
The effects of the deep cryogenic heat treatment on the microstructural changes, wear resistance, and hardness of carburized DIN 1.7131 grade steel were investigated. Results show that cryogenic heat treatment reduced the retained austenite and increased the carbide amount. In addition, after the cryogenic heat treatment, carbide shows a more uniform distribution, as compared to the conventionally treated ones. It was also clarified that the hardness of the cryogenically treated samples was improved, but the relative improvement decreases with the distance as the surface increases. It has been shown that the wear resistance improves due to the cryogenic heat treatment, and the predominant wear mechanism is a combination of the adhesive and tribo-chemical wear.
\end{abstract}

\section{KEY WORDS: DIN 1.7131 grade steel; Carburized steel; Hardness; Deep cryogenic heat treatment} Tribo-chemical wear

\section{Introduction}

Cryogenic heat treatment was introduced to the industries in the second decade of the twentieth century. This special kind of supplementary heat treatment plays an important role in selecting the finishing production procedure of the parts with the lowest wear rate, austenite percentage, and economic cost [1-7]. This specific heat treatment is characterized into two different groups: (1) the shallow cryogenic heat treatment performed at temperatures higher than $125 \mathrm{~K}$ and (2) the deep cryogenic heat treatment attributed

Available online at http://link.springer.com/journal/40195

\section{K. Amini $(\bowtie)$}

Department of Materials Science, Majlesi Branch, Islamic Azad

University, Isfahan, Iran

e-mail: k.amini@iaumajlesi.ac.ir

A. Araghi · A. Akhbarizadeh

Department of Materials Science and Engineering, Shiraz

Branch, Islamic Azad University, Shiraz, Iran to the treatments in which samples are cooled to the lower temperatures $(125-77 \mathrm{~K})[1,2,4,8]$.

The main effect of the cryogenic heat treatment is the reduction or elimination of the retained austenite. The other effect that only takes place at the deep cryogenic temperatures is the reduction of the carbides size, increasing its percentage, and making a more homogenous carbide distribution $[1,9,10]$. These microstructural changes are a consequence of carbon atoms jumping at the low temperature due to the high degree of contraction in the martensite structure. The structure contraction at low temperatures forces the carbon atoms to jump to the nearby defects. These defects act as an appropriate place for the eta chromium carbide nucleation in the prior tempering. These new carbides increase the carbides percentage and make a more uniform carbide distribution in the material after the deep cryogenic treatment $[2,4,6,11-16]$.

The deep cryogenic heat treatment involves a wide variety of materials, including carburized steels [17-21], high-speed steels [22-24], composites and polymers [25], and the tool steels which are the most attractive areas of researches. Numerous studies were conducted on tool 
steels, including M, O, T, and D series $[1,6,9,15,16,26-$ 29].

Investigations showed that the deep cryogenic heat treatment improves the carburized steels mechanical properties. Carburizing increases the retained austenite percentage due to its effect on decreasing the martensite finish temperature $\left(M_{\mathrm{f}}\right)$. This retained austenite would decrease after the deep cryogenic heat treatment, and hence, the hardness is improved. Moreover, increasing the carbon content of a structure produces further distortions during quenching. These distortions increase the carbide percentage additionally after the deep cryogenic heat treatment. These phenomena increase the hardness and wear resistance of the carburized steels after the deep cryogenic heat treatment $[2,10,17-21,30]$. Despite these studies, there is an antithesis about the effectiveness of carburization before the deep cryogenic heat treatment. In this study, the effect of the deep cryogenic heat treatment on the wear behavior and microstructural changes of DIN 1.7131 grade steel which is vastly used in mandrels and steer components was investigated via scanning electron microscopy (SEM), energy-dispersive spectroscopy (EDX), X-ray diffraction (XRD), and pin-on-disk wear test.

\section{Experimental}

A 50-mm bar of DIN 1.7131 grade steel with the nominal composition of (wt\%): $0.15 \mathrm{C}, 0.33 \mathrm{Si}, 1.06 \mathrm{Mn}, 0.95 \mathrm{Cr}$, $0.005 \mathrm{P}, 0.009 \mathrm{Si}$, and balance of $\mathrm{Fe}$ was cut into the disks of $5 \mathrm{~mm}$ in height. The samples were then carburized in a cyanide bath at $900{ }^{\circ} \mathrm{C}$ for $6 \mathrm{~h}$ and then quenched in air. The samples were then austenized at $920{ }^{\circ} \mathrm{C}$ for $15 \mathrm{~min}$ followed by oil quenching. One group of samples was then immediately deep cryogenically treated at $-195{ }^{\circ} \mathrm{C}$ for $24 \mathrm{~h}$. For the deep cryogenic heat treatment, the samples were cooled down from room temperature with the cooling rate of $1{ }^{\circ} \mathrm{C} / \mathrm{min}$ and then held at that temperature for $24 \mathrm{~h}$. The samples were then gradually warmed up to room temperature. These samples were named deep cryogenically treated (DCT) samples and the other samples conventionally heat treated which were named $\mathrm{CHT}$ samples. The whole samples were then tempered at $150{ }^{\circ} \mathrm{C}$ for $1 \mathrm{~h}$. Schematic diagram of heat treatment of the DCT samples is shown in Fig. 1.

To study the microstructural changes of the samples, the samples surface was etched in $4 \mathrm{vol} \%$ nital solution (96 $\mathrm{mL}$ ethanol and $4 \mathrm{~mL} \mathrm{HNO}_{3}$ ). The samples surfaces were then analyzed via a scanning electron microscope (SEM Ser on AIS-2100) and an optical microscope (OMOlymuos).

The X-ray diffraction (XRD) with $\mathrm{Cu} K_{\alpha}$ radiation was used to clarify the phases and the retained austenite

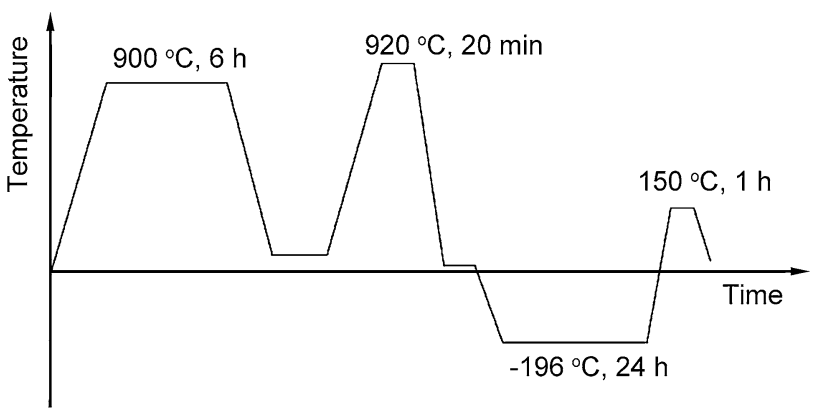

Fig. 1 Schematic diagram of heat treatment of the DCT samples

fraction. The retained austenite percentage was calculated with respect to the ASTM E975-00 standard [31]. The carbide percentage was evaluated via the SEM micrographs and the austenite percentage and was calculated using the following equation [31]:

$V_{\gamma}=\frac{\left(1-V_{\mathrm{c}}\right)\left(\frac{1}{q} \sum_{j=1}^{q}\left(\frac{I_{\nu j}}{R_{\gamma j}}\right)\right)}{\frac{1}{p} \sum_{i=1}^{p}\left(\frac{I_{x i}}{R_{x i}}\right)+\frac{1}{q} \sum_{j=1}^{q}\left(\frac{I_{i j}}{R_{j j}}\right)} \times 100 \%$,

where $V_{\gamma}$ and $V_{\mathrm{c}}$ are the retained austenite and carbide percentages, respectively, $q$ and $p$ are the number of austenite and martensite peaks; $I_{\gamma}$ and $I_{\alpha}$ are the integrated intensity per angular diffraction peak $(h k l)$ in the austenite and martensite phases, respectively, $R_{\gamma}$ and $R_{\alpha}$ are the austenite and martensite constants, respectively. The value of $R$ can be calculated with respect to the $(h k l)$ plane in combination with the polarization, multiplicity, and structure factor of the phases according to the ASTM E975-00 standard [31]:

$R=\frac{1}{v^{2}}\left[\left|F^{2}\right| P\left(\frac{1+\cos ^{2} 2 \theta}{\sin \theta \sin 2 \theta}\right)\right] \mathrm{e}^{-2 M}$,

where $v$ is the unit volume, $F$ is the structure factor, $\mathrm{e}^{-2 M}$ is the temperature constant, and $P$ is the multiplicity factor. For further studies, the carbides types were also examined via energy-dispersive spectroscopy (EDX, Seron AIS2100).

The hardness of the samples was evaluated as the Vickers method via a KOOPA UV1 hardness tester with the applied load of $4.9 \mathrm{~N}$ with respect to the ASTM E384 and ASTM E92 standards. Each sample was tested for 10 times to reach a reliable hardness average.

The wear tests were carried out by a pin-on-disk wear tester with $68 \mathrm{HRC}$ steel pins at $(25 \pm 5){ }^{\circ} \mathrm{C}$ with $(30 \pm 10) \%$ humidity and the applied loads of 160 and $120 \mathrm{~N}$ at the sliding velocity of $0.1 \mathrm{~m} / \mathrm{s}$. The sliding distance was $1,000 \mathrm{~m}$, and the samples weight loss was calculated via an electronic balance with an accuracy of $0.0001 \mathrm{~g}$. Each group of samples was tested for two times to reach a trustful result. The wear rate was calculated by 
$W_{r}=\Delta m /\left(\rho L F_{\mathrm{N}}\right) \times 10^{3}$,

where $W_{\mathrm{r}}$ is the wear rate in $\mathrm{mm}^{3} /(\mathrm{N} \mathrm{m}) ; \Delta m$ is the weight loss in $\mathrm{g} ; \rho$ is the steel density in $\mathrm{g} / \mathrm{cm}^{3} ; L$ is the wear distance in $\mathrm{m}$; and $F_{\mathrm{N}}$ is the load in $\mathrm{N}$.

The worn-out surface of the samples was analyzed via SEM to study the extent of wear damages and the topography of the surface, as well as clarifying the predominant wear mechanism.

\section{Results and Discussion}

Figure 2 shows the XRD patterns of the DCT and CHT samples. It can be conducted that deep cryogenic heat treatment eliminates the retained austenite from $15 \%$ in the CHT samples to a percentage lower than the detection limit of the XRD technique $(<1 \%)$ in the DCT samples. It was clarified that the austenite (110) and (110) peaks are eliminated in the DCT sample. The XRD patterns of the samples show that in addition to the austenite and martensite, chromium carbide exists in the structure.

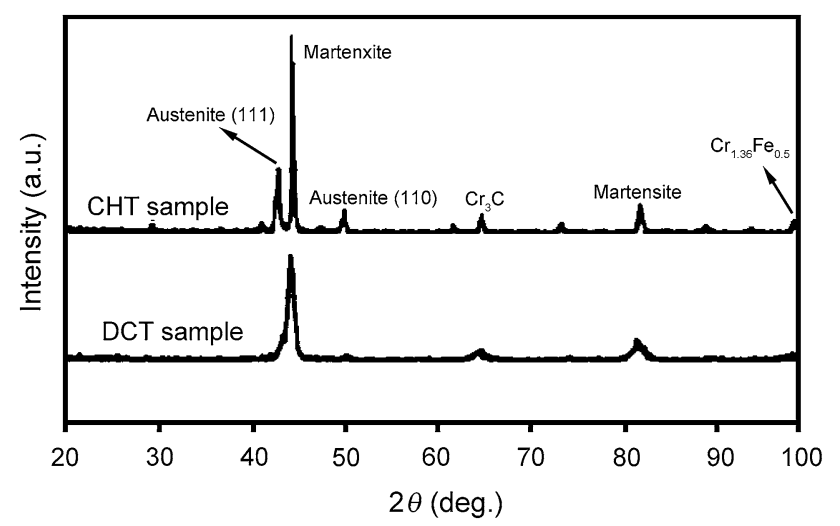

Fig. 2 XRD patterns of the DCT and CHT samples
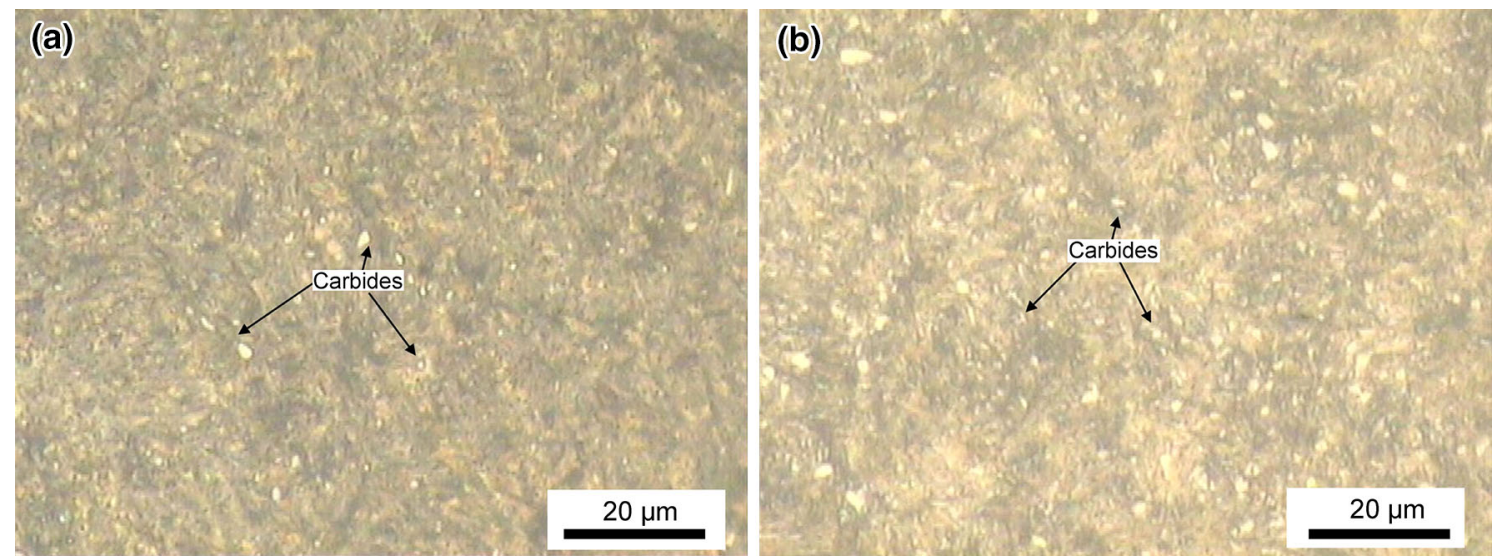

Figures 3 and 4 show the OM and SEM micrographs of the surfaces of DCT and CHT samples, respectively. It is found that deep cryogenic heat treatment increases the carbide percentage from $2 \%$ in the CHT samples to $7 \%$ in the DCT samples. At low temperatures, the martensite structure is contracted. The contraction quantities of austenite and martensite are different, and hence, some defects are produced in the austenite-martensite boundaries. The contraction forces the carbon atoms in the highly saturated and contracted BCT structure of martensite to jump to the nearby defects. These atoms would act as the preferential nucleation sites for carbide nucleation during tempering [1, 2, 4, 26]. Carburizing enhanced the tendency of carbon atoms to jump to the nearby defects due to its effect on the martensite structure distortion. Increasing the carbon content of a martensite structure leads to a decrease in the structure meta-stability due to increasing the structure $c /$ $a$ ratio in the unit cell [1-3]. Thus, carburizing increases the carbon atoms tendency in jumping to nearby defects at low temperatures. This phenomenon in cooperation with the traditional effect of the deep cryogenic heat treatment on the martensite structure increases the carbides percentage in the DCT samples vividly. Moreover, the carbides show a more uniform distribution, as compared to the CHT samples due to the tendency of the structure for relaxation at low temperatures during the deep cryogenic treatment (Fig. 4).

Decreasing the retained austenite, increasing the carbide percentage and improving the carbide homogenous distribution increase the hardness of the DCT samples for $10 \%$, as compared to the CHT samples, as shown in Fig. 5. From Fig. 5, it can be seen that hardness was also evaluated at different distances from the surface. It was clarified that the effect of deep cryogenic treatment decreases vividly in the lower layers due to the fact that a decrease takes place in carbon content of the samples. Carburizing increases the carbon content of the samples surface. In deeper layers, the

Fig. 3 OM micrographs of the CHT a, DCT b samples 

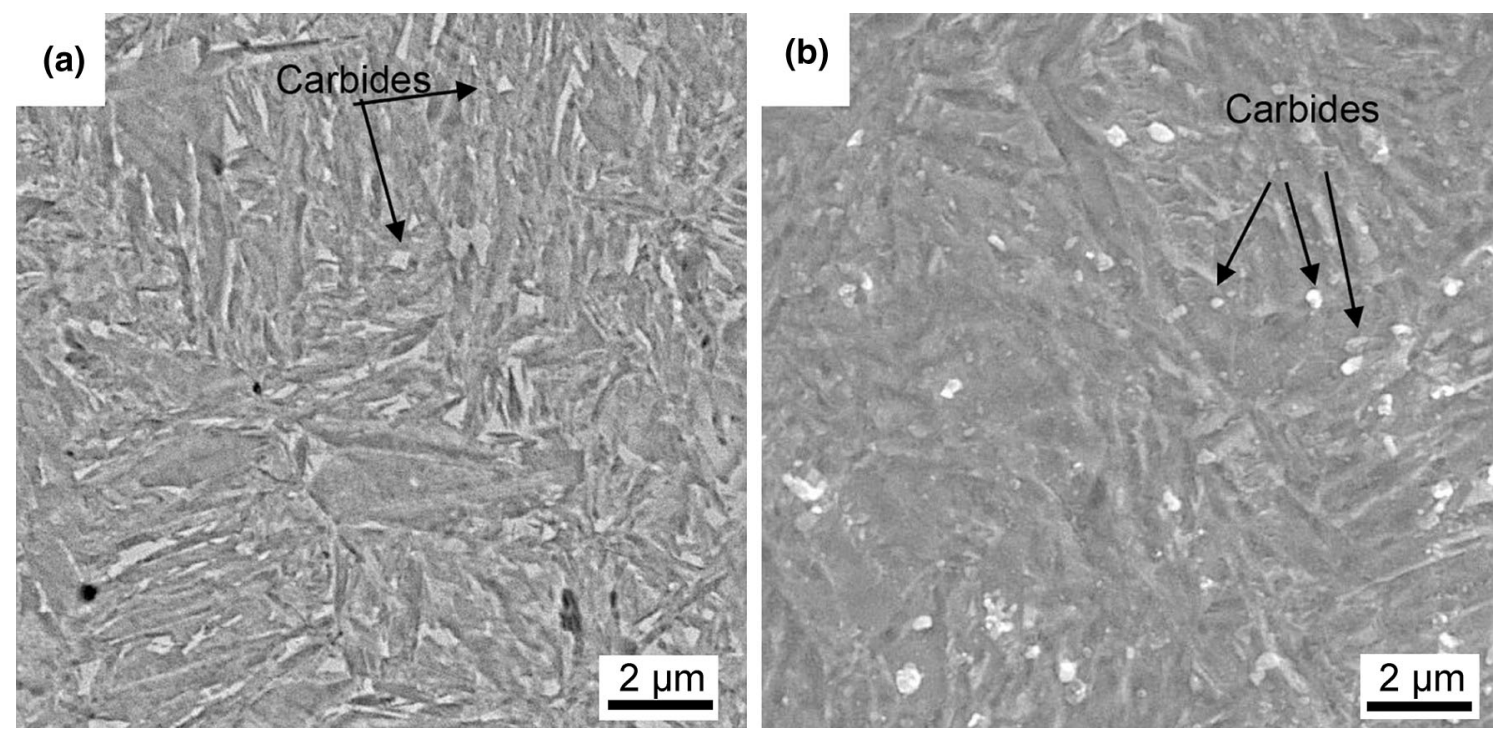

Fig. 4 SEM images of the CHT a, DCT b samples

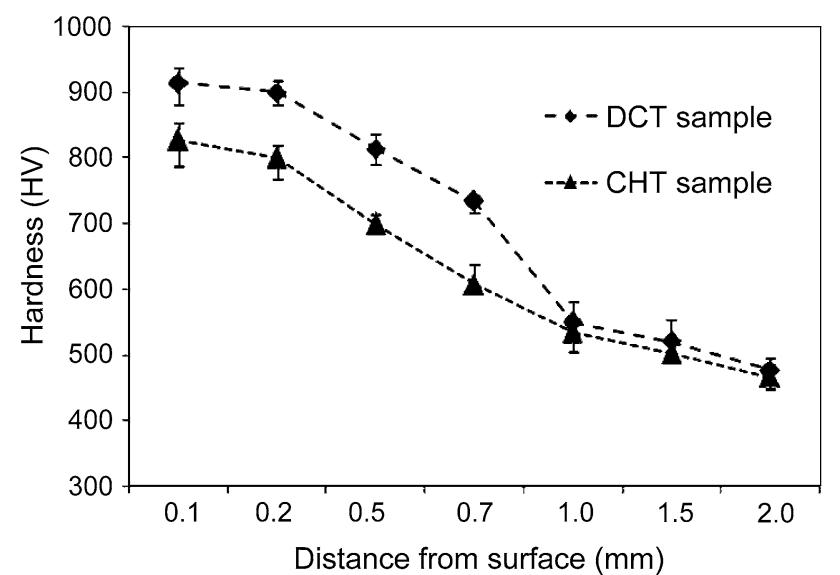

Fig. 5 Variation of hardness in the DCT and CHT samples as a function of distance from the samples surface

carbon content decreases due to lack of diffusion. Figure 5 shows that the difference between the hardness of the DCT and CHT samples decreases as a function of distance from the samples surface. After about $1 \mathrm{~mm}$ from the surface, the hardness of DCT and CHT samples shows a similar trend.

At higher contents of carbon, the effect of deep cryogenic heat treatment is more obvious due to the greater distortion produced in the martensite structure. Higher carbon increases the structure tendency in forcing the carbon atoms to jump to the nearby defects, thereby increases the hardness more vividly. In the depths more than $1 \mathrm{~mm}$ from the surface, the hardness of the DCT samples shows a slight improvement as compared to the CHT samples in the same depth. This behavior is a consequence of the retained austenite annihilation. Nevertheless, this variation is not so vivid due to the low content of carbon atoms in the lower layers. In other words, higher carbon content is a key factor in the deep cryogenic heat treatment and this treatment is not beneficial in the low-carbon steels.

The wear rate of the samples shows that deep cryogenic heat treatment improves the wear resistance by $21 \%-25 \%$
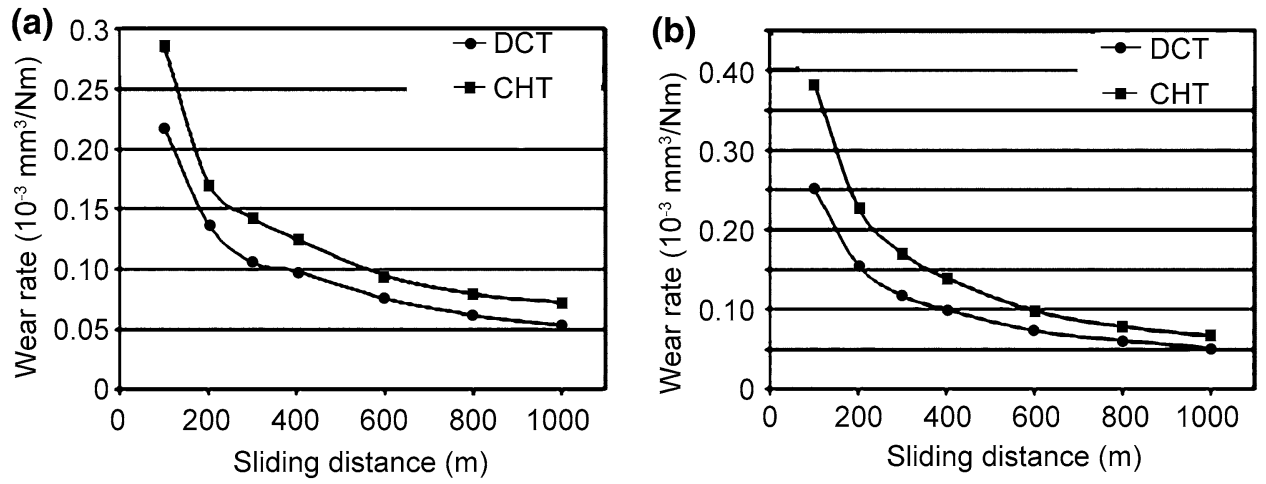

Fig. 6 Variation of wear rate versus the sliding distance at the loads of $120 \mathrm{~N} \mathrm{a}, 160 \mathrm{~N} \mathrm{~b}$ 

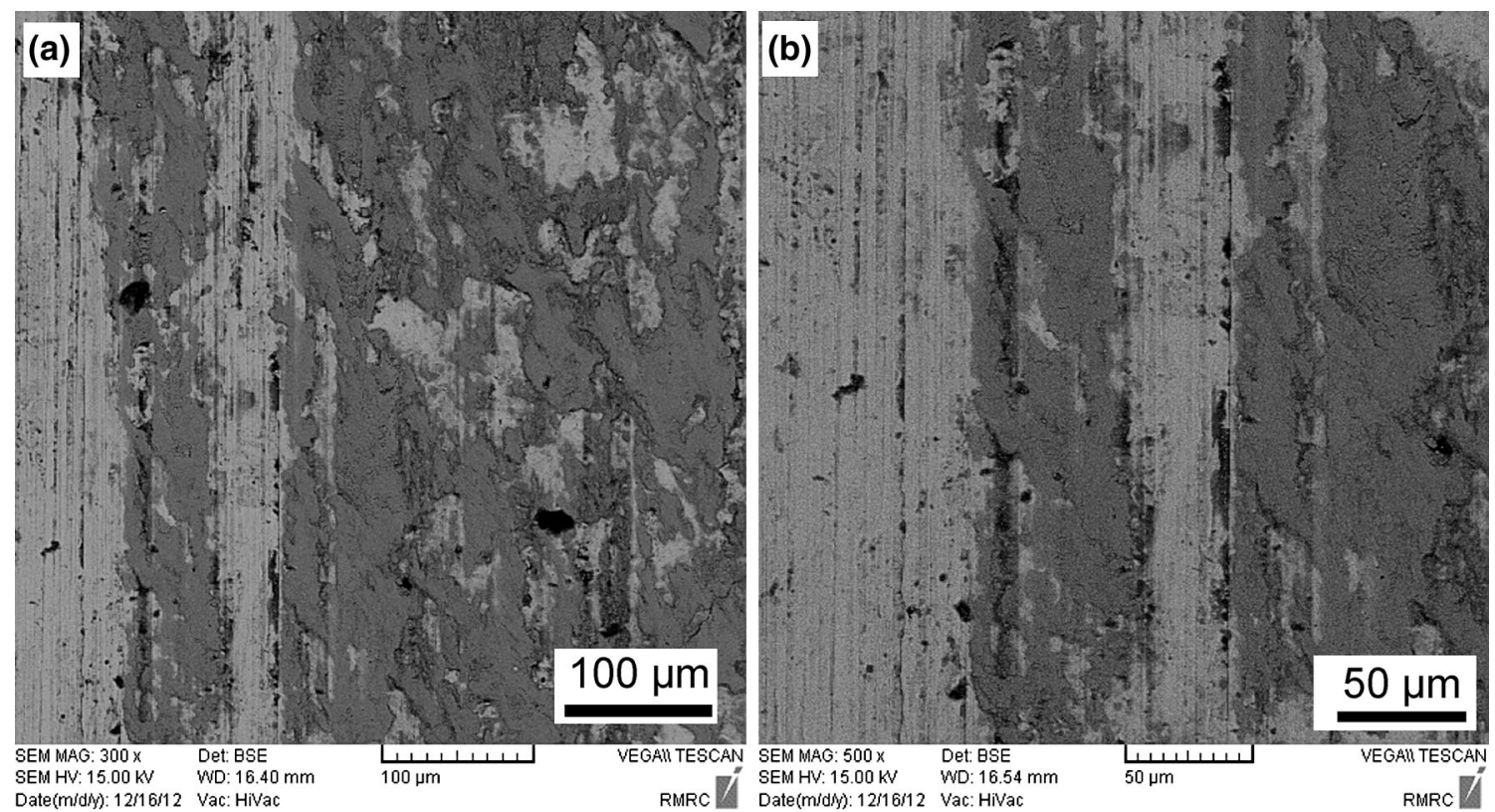

Fig. 7 SEM images of the worn-out surfaces of DCT a, CHT b samples after $500 \mathrm{~m}$ sliding under the load of $120 \mathrm{~N}$
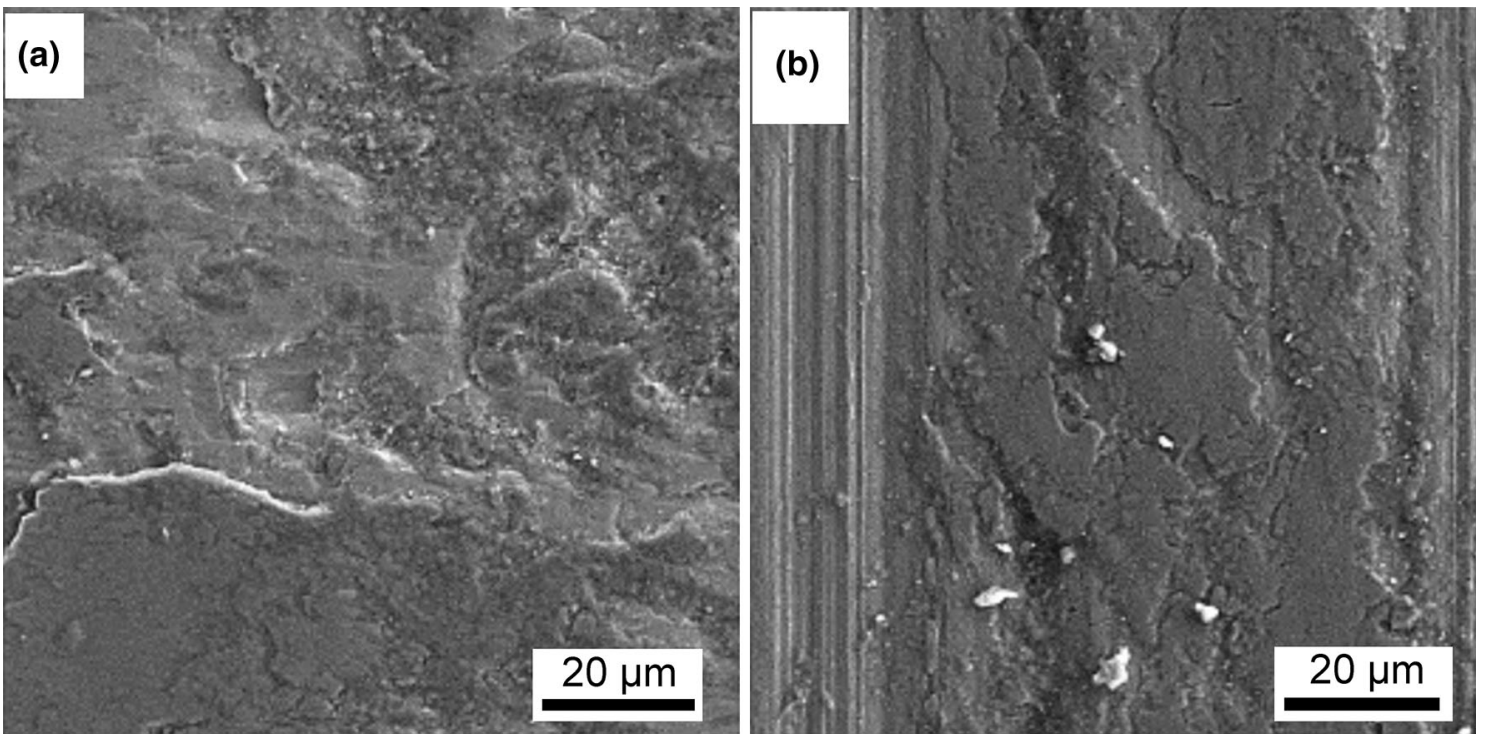

Fig. 8 SEM images of the worn-out surfaces of the DCT samples after 1,000 m sliding under the loads of $160 \mathrm{~N} \mathrm{a,} 120 \mathrm{~N} \mathrm{~b}$

in the DCT samples, as compared to the CHT ones, as shown in Fig. 6. This improvement is a consequence of the retained austenite elimination, as well as increasing the carbide percentage and making a more uniform carbide distribution in the DCT samples. Increasing the applied load in the wear test from 120 to $160 \mathrm{~N}$, the wear rate increases due to the severe compaction between the sliding surfaces. In both of the loads (120 and $160 \mathrm{~N})$, the DCT samples show better wear resistance as compared to the conventionally treated ones.
The SEM micrographs of the worn-out surface of the samples show that the predominant wear mechanism is adhesive, as shown in Fig. 7. The worn-out surface of the DCT samples shows a less destroyed feature, as compared to that of the CHT ones. Moreover, the worn-out surface of the DCT samples at higher loads $(160 \mathrm{~N})$ shows a more destructed feature with more roughness due to the higher compaction force at higher loads, as shown in Fig. 8. Moreover, Fig. 9 is the EDX analysis of the samples, which shows that a high degree of oxygen is observed in 

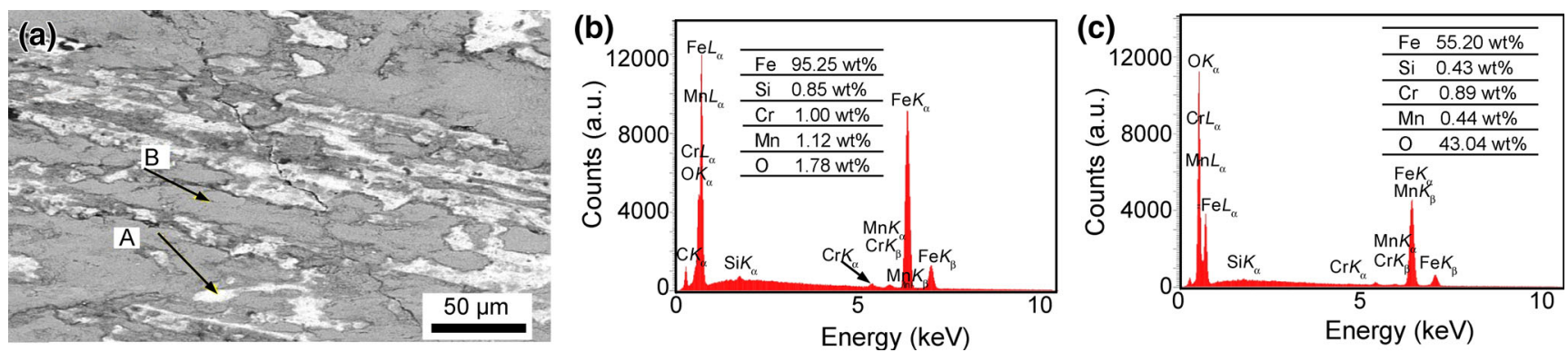

Fig. 9 SEM image of the worn-out surface of the DCT sample after 1,000 $\mathrm{m}$ sliding under $120 \mathrm{~N}$ load $\mathbf{a}$, EDX results of points A b, B $\mathbf{c}$ in Fig. 9a

the worn-out surface of the samples. This phenomenon is a consequence of the tribo-chemical wear mechanism during the wear test. During the wear test, a highly localized temperature rise produces the surface oxide in the samples surface, increasing the wear rate due to deamination.

\section{Conclusions}

1. Deep cryogenic heat treatment eliminated the retained austenite, as well as increasing the carbide percentage by $5 \%$ for carburized DIN 1.7131 grade steel. Also the carbide shows a more uniform distribution after the deep cryogenic treatment.

2. The hardness of the samples improves by $10 \%$ after the deep cryogenic heat treatment. The hardness differences between the deep cryogenically and conventionally treated samples decrease in the lower layers of the samples due to a decrease in the carbon content. This decrease in the lower layers is a consequence of lower diffusion of carbon atoms during the carburizing process.

3. The wear rate of the deep cryogenically treated samples improves by $21 \%-25 \%$ in different loads of 120 and $160 \mathrm{~N}$. It was also clarified that the predominant wear mechanism is a combination of adhesive and tribo-chemical wear.

Acknowledgments The authors are thankful to the Majlesi Branch, Islamic Azad University for the support of this work.

\section{References}

[1] N.S. Kalsi, R. Sehgal, V.S. Sharma, Mater. Manuf. Process. 25, 1077 (2010)

[2] D. Collins, Heat Treat. Met. (UK) 23, 40 (1996)

[3] P. Cohen, D. Kamody, Cut. Tool Eng. 50, 46 (1998)

[4] D. Das, A.K. Dutta, K.K. Ray, Mater. Sci. Eng. A 527, 2182 (2010)

[5] D. Das, A.K. Dutta, K.K. Ray, Wear 266, 297 (2009)
[6] J.Y. Huang, Y.T. Zhu, X.Z. Liao, I.J. Beyerlein, M.A. Bourke, T.E. Mitchell, Mater. Sci. Eng. A 339, 241 (2003)

[7] W. Reitz, J. Pendray, Mater. Manuf. Process. 16, 829 (2001)

[8] D. Das, A.K. Dutta, K.K. Ray, Mater. Sci. Eng. A 527, 2194 (2010)

[9] S. Gill, J. Singh, R. Singh, H. Singh, Int. J. Adv. Manuf. Technol. 54, 59 (2011)

[10] C.D.P. Baldissera, Open Mech. Eng. J. 2, 1 (2008)

[11] S. Kalia, J. Low, Temp. Phys. 158, 934 (2010)

[12] F. Cajner, V. Leskovšek, D. Landek, H. Cajner, Mater. Manuf. Process. 24, 743 (2009)

[13] P. Stratton, M. Graf, Cryogenics 49, 346 (2009)

[14] S. Zhirafar, A. Rezaeian, M. Pugh, J. Mater. Process. Technol. 186, 298 (2007)

[15] A. Oppenkowski, S. Weber, W. Theisen, J. Mater. Process. Technol. 210, 1949 (2010)

[16] A.I. Tyshchenko, W. Theisen, A. Oppenkowski, S. Siebert, O.N. Razumov, A.P. Skoblik, V.A. Sirosh, Y.N. Petrov, V.G. Gavriljuk, Mater. Sci. Eng. A 527, 7027 (2010)

[17] P. Baldissera, C. Delprete, Mater. Des. 30, 1435 (2009)

[18] A. Bensely, D. Senthilkumar, D. Mohan Lal, G. Nagarajan, A. Rajadurai, Mater. Charact. 58, 485 (2007)

[19] A. Bensely, L. Shyamala, S. Harish, D. Mohan Lal, G. Nagarajan, K. Junik, A. Rajadurai, Mater. Des. 30, 2955 (2009)

[20] A. Bensely, S. Venkatesh, D. Mohan Lal, G. Nagarajan, A. Rajadurai, K. Junik, Mater. Sci. Eng. A 479, 229 (2008)

[21] M. Preciado, P.M. Bravo, J.M. Alegre, J. Mater. Process. Technol. 176, 41 (2006)

[22] F.J. Da Silva, S.D. Franco, Á.R. Machado, E.O. Ezugwu, A.M. Souza Jr, Wear 261, 674 (2006)

[23] V. Firouzdor, E. Nejati, F. Khomamizadeh, J. Mater. Process. Technol. 206, 467 (2008)

[24] V. Leskovšek, M. Kalin, J. Vižintin, Vacuum 80, 507 (2006)

[25] J. Indumathi, J. Bijwe, A.K. Ghosh, M. Fahim, N. Krishnaraj, Wear 225-229, 343 (1999)

[26] K.E. Moore, N. Collins, Key Eng. Mater. 86-87, 47 (1993)

[27] P.F. Stratton, Mater. Sci. Eng. A 449-451, 809 (2007)

[28] T.K.F. Meng, R. Azuma, H. Sohma, ISIJ Int. 34, 205 (1994)

[29] D. Das, A.K. Dutta, K.K. Ray, Philos. Mag. Lett. 88, 801 (2008)

[30] A. Bensely, A. Prabhakaran, D. Mohan Lal, G. Nagarajan, Cryogenics 45, 747 (2005)

[31] ASTM, Standard Practice for X-Ray Determination of Retained Austenite in Steel with Near Random Crystallographic Orientation (ASTM International, West Conshohocken, 2013) 